\title{
NOTAS SOBRE A NARRATIVA COMO INSTRUMENTO DE INTERVENÇÃO EM CONTEXTO DE SAÚDE INFANTOJUVENIL
}

RUZIA CHAOUCHAR DOS SANTOS

Universidade Federal de Mato Grosso

NAIANA MARINHO GONÇALVES

Universidade Federal de Mato Grosso

HENRIQUE ARAUJO ARAGUSUKU

Universidade Federal de Mato Grosso

DANIELA BARROS DA SILVA FREIRE ANDRADE

Universidade Federal de Mato Grosso

RESUMO O presente trabalho tem como objetivo investigar o potencial da narrativa enquanto instrumento de intervenção psicológica em um CAPSI, a partir da apresentação de um estudo de caso individual. As elaborações teórico-reflexivas fundamentam-se na Teoria das Representações Sociais (DUVEEN; LLOYD, 2008), em diálogo com a Teoria Histórico-Cultural (AGUIAR; OZELLA, 2006; MOLON, 1999; PRESTES, 2010; VIGOTSKI, 2009; 2010a; 2010b). Além dos estudos sobre narrativas (BRUNER, 1997; 2001; 2002; JOVCHELOVITCH; BAUER, 2002). Os dados discutidos foram engendrados nas análises das intervenções realizadas em oficinas socioafetivas (ANDRADE, 2015), tematizadas diante da apresentação de uma narrativa, através da qual propôs-se a construção de uma narrativa coletiva a um grupo de adolescentes. As múltiplas faces da narrativa criada por uma adolescente foram identificadas no primeiro momento do processo, quando esteve em pauta a idealização do estado de bem-estar, saúde e felicidade, em contraposição à caracterização de sua condição de usuária, cujas narrativas são registradas em prontuário - narrativas defensivas. No segundo momento, observou-se a emergência de narrativas espontâneas, quando ela assume seu papel de protagonista na produção do enredo coletivo, liberta-se das preocupações relativas ao protocolo de tratamento e anuncia conteúdos e conflitos juntamente 
com metáforas que deixam ver seu processo de enfrentamento do desconhecido.

Palavras-chave: Narrativa. Infantojuvenil. Saúde Mental.

The present study aims to investigate the potential of narrative as a psychological intervention instrument in a CAPSI, through the presentation of an individual study case. The theoretical-reflective elaborations are based on the Theory of Social Representation (DUVEEN \& LLOYD, 2008) in dialogue with the Historical-Cultural Theory (AGUIAR \& OZELLA, 2006; MOLON, 1999; PRESTES, 2010; VIGOTSKI, 2009, 2010a, 2010b). In addition to the studies on narrative (BRUNER, 1997, 2001, 2002; JOVCHELOVITCH; BAUER, 2002). The research data discussed were engendered in the analysis of interventions made in social-affective workshops (ANDRADE, 2015), themed on the presentation of a narrative whereby the constrution of a collective narrative to a group of teenagers were proposed. The narrative multiple faces created by the teenager were identified in the first moment of the process, when the idealization of the walfare, health and happiness as opposition to the characterization of her user condition was on the agenda, whose narratives are recorded in the medical records - defensive narratives. In the second moment, the emergence of spontaneous narratives were observed, when she takes her starring role in the production of the collective plot, free herself from the concerns regarding the treatment protocol and announces contents and conflicts whitin metaphors that explicit her process of challenge the unknown.

Keywords: Narrative. Children \&Youth. Mental Health.

El presente trabajo tiene como objetivo investigar el potencial de la narrativa como instrumento de intervención psicológica en un CAPSI, a partir de la presentación de un estudio individual de caso. Las elaboraciones teórico-reflexivas se basan en la Teoría de las Representaciones Sociales (DUVEEN \& LLOYD, 2008), en diálogo con la Teoría Histórico-Cultural (AGUIAR \& OZELLA, 2006; MOLON, 1999; PRESTES, 2010; VIGOTSKI, 2009, 2010a, 2010b). Además de los estudios acerca narrativas (BRU- 
NER, 1997, 2001, 2002; JOVCHELOVITCH; BAUER, 2002). Los datos analizados fueron engendrados en el análisis de las intervenciones en talleres socio-afectiva (ANDRADE, 2015), temática sobre la presentación de una narrativa, a través del cual fue propuesto la construcción de una narrativa colectiva a un grupo de adolescentes, Las múltiples faces de la narrativa creadas por la adolescente, foram identificadas en el primer momento del proceso, cuando estaba en la agenda la idealización del estado de bienestar, la salud y la felicidad en contraposición a la caracterización de su condición de usuaria, cuyas narrativas se registran en los registros médicos - narrativas defensivas. En segundo momento, fue observada la aparición de narrativas espontáneas, cuando ella toma su papel protagonista en la produción de la trama colenarrctiva, se libera de las preocupaciones con respecto al protocolo de tratamiento y anuncia contenidos y conflictos junto a las metáforas que explicitan su proceso de afrontamiento de lo desconocido.

Palabras clave: Narrativa. Infanto-Juvenil. Salud Mental.

\section{Introdução}

0 presente trabalho apoia-se na abordagem psicossocial e se propõe a investigar o potencial da narrativa, enquanto um instrumento de intervenção psicológica, capaz de suscitar processos terapêuticos em um Centro de Atenção Psicossocial Infantojuvenil (CAPSI), do município de Cuiabá-MT, a partir da apresentação de um estudo de caso individual.

Este estudo é proveniente de vivências acadêmicas inseridas no Projeto de Extensão intitulado Rede de Apoio à Educação Infantil: interfaces com a Psicologia e Pedagogia, desenvolvido durante as disciplinas de Estágio Supervisionado Específico I e II: Intervenções em Processos de Saúde e Sofrimento Psíquico, realizadas por três estagiários, no transcorrer do nono e décimo semestres de Psicologia da Universidade Federal de Mato Grosso (UFMT), campus Cuiabá-MT.

Nesta perspectiva, as intervenções realizadas junto a um grupo terapêutico de adoles- cente do CAPSI Curumim, localizado no município de Cuiabá-MT, priorizaram a abordagem psicossocial e se propuseram a investigar o potencial da narrativa encorajadora, enquanto instrumento psicológico de mediação e promoção de desenvolvimento, capaz de incitar processos terapêuticos, no âmbito do cuidado à Saúde Mental. As narrativas encorajadoras são aquelas que possuem o potencial de estimular a continuidade ou a criação de enredos imprevisíveis, a partir da proposição de uma narrativa semiacabada, baseada na utilização de ferramentas para mediar as interações sociais, dentre elas, imagens, pequenas histórias, situações problema, filmes e músicas (ANDRADE, 2015).

Diante disso, a opção pelo trabalho com a adolescência foi delineada a partir de uma proposta da referida unidade de saúde, em parceria com o Grupo de Pesquisa em Psicologia da Infância (GPPIN). A demanda de traba- 
lho apresentada estava vinculada às dificuldades em pensar o espaço como um lugar para adolescentes, visto que muitas das crianças que eram atendidas se tornaram adolescentes demandando um reposicionamento do olhar à elas/es direcionado. Assim, havia uma demanda para se construir um lugar para adolescentes, de modo a ampliar o sentimento de pertença destes grupos para com o CAPSI e sua equipe.

É fundamental apontar que o contexto deste ensaio compreende a adolescência enquanto categoria socialmente construída, em contraposição a significações, de caráter universal, essencialista, naturalizante e a-históricas, que a concebem enquanto período do desenvolvimento humano, atravessado pela ideia de crise, vulnerabilidade acentuada, conflitos, rebeldia, atrevimento e irresponsabilidade. Ao ancorar o estudo na abordagem psicossocial, parte-se da concepção de que a categoria adolescência deve ser pensada a partir de uma relação dialética entre as dimensões social e histórica deste fenômeno, que é construído, interpretado e significado pelo ser humano. (AGUIAR; OZELLA, 2008).

As elaborações teórico-reflexivas fundamentam-se na Psicologia Social, em interlocução com a Psicologia da Educação e do Desenvolvimento. Tal diálogo teórico permite pensar na desconstrução do paradigma clínico tradicional, enquanto o único possivel em uma unidade de atenção à saúde mental. No que se refere às dimensões da aprendizagem e do desenvolvimento, o estudo apoiou-se na Teoria Histórico-Cultural, conforme Vigotski (2009; 2010a; 2010b), Prestes (2010) e Molon (1999; 2000; 2011), além das considerações de Aguiar e Ozella (2006) acerca dos conceitos de sentido e significado.

Por sua vez, as contribuições da Psicologia Social compreenderam a articulação com a Teoria das Representações Sociais, sendo pri- vilegiada neste contexto, a Abordagem Ontogenética das Representações Sociais, de acordo com Duveen e Lloyd (2008).

Acrescentam-se as reflexões baseadas nos estudos sobre narrativas, realizados por Bruner (1997; 2001; 2002), e as considerações de Jovchelovitch e Bauer (2002) acerca da temática, possibilitando compreender a narrativa enquanto um instrumento psicológico de mediação, que pode potencializar processos terapêuticos.

O percurso metodológico adotado inicialmente está baseado na técnica da observação participante e, posteriormente, na realização de oficinas socioafetivas, que privilegiaram como ferramentas de intervenção a narrativa e a ludicidade. Os conteúdos oriundos das intervenções psicossociais serão considerados a partir de uma análise compreensiva dos fenômenos encontrados, sendo delineados enquanto um Estudo de Caso.

\section{Apontamentos sobre o papel da}

\section{narrativa no desenvolvimento}

\section{humano}

Ao conceber a adolescência com base na perspectiva psicossocial e histórico-cultural, é possivel realizar um diálogo com os estudos sobre narrativa, propostos por Bruner (1997; 2001; 2002), além das contribuições de Jovchelovitch e Bauer (2002) sobre a temática. Esta interlocução teórica propõe ao(a) leitor(a) uma reflexão acerca da opção pela narrativa, enquanto instrumento de intervenção psicossocial, que se baseia no reconhecimento do processo discursivo do sujeito, seja ele incoerente, fragmentado e contraditório aos padrões normativos da sociedade. 0 recorte anunciado neste trabalho tem como intuito desconstruir o binômio normalidade/anormalidade ancorado no paradigma manicomial, que, ainda nos dias atuais, influencia a atenção à Saúde Mental. 
De acordo com Bruner (1997), o ser humano apresenta uma propensão para organizar a experiência social pela via da narrativa. Sobre este aspecto, Jovchelovitch e Bauer (2002), ao citarem Roland Barthes, apontam que toda experiência pode ser expressa por esta forma discursiva que é infinita em sua variedade e universal. Nas palavras destes autores,

[...] a narrativa está presente em cada idade, em cada lugar, em cada sociedade; ela começa com a própria história da humanidade e nunca existiu, em nenhum lugar e em tempo nenhum, um povo sem narrativa. Não se importando com a boa ou má literatura, a narrativa é internacional, trans-histórica, transcultural: ela está simplesmente ali, como a própria vida. (2002, p. 91)

Bruner (1997), esclarece que uma das formas de ter acesso e interpretar os dados da cultura é pelo discurso narrativo, que promove a mediação da própria experiência e configura a construção da realidade. Nessa perspectiva, torna-se importante acrescentar que, tanto a cultura como seus artefatos culturais podem ser apreendidos como "[...] o modo de vida e pensamento que construímos, negociamos e institucionalizamos e que, por fim (depois que tudo estiver resolvido), acaba por se chamar 'realidade"' (BRUNER, 2001, p. 89).

Neste sentido, as concepções elucidadas sobre os estudos de narrativa, se aproximam dos pressupostos da teoria vigotskiana, que compreende o ser humano enquanto aquele que se constitui e também é constituído pelo meio, trazendo em si relações de historicidade, ideologia e representações da sociedade. (AGUIAR; OZELLA, 2006).

Desta forma, no sentido de compreender a relação do sujeito com o seu entorno social, entende-se que é fundamental discutir a concepção de meio e o seu papel no desenvolvimento humano. Para Vigotski (2010b), não há a separação entre meio e pessoa, porque toda situação vivenciada é vivida em um meio so- cial. Seguindo a referida reflexão, este meio deve ser analisado a partir de parâmetros relativos, e não por intermédio de parâmetros absolutos. Uma vez que, para uma criança em determinada fase de seu desenvolvimento, os elementos do meio terão uma função, e para a mesma criança, inserida no mesmo meio, mas com diferente faixa etária e em outras circunstâncias, este mesmo contexto exercerá outra função, visto que o desenvolvimento possibilita a formação de novas relações da criança consigo mesma e com o meio.

Nesse sentido, torna-se necessário abordar a relação do sujeito com o meio, a partir do conceito de vivência' (VIGOTSKI, 2010b). Esta por sua vez, é considerada uma unidade de um todo complexo que se configura enquanto uma unidade regente das particularidades do sujeito com as particularidades do meio, da maneira como está representada em seu desenvolvimento.

Em consonância com este pensamento, faz-se pertinente retomar a contribuição do conceito de cultura em Bruner, o qual expõe que “[...] embora os significados estejam 'na mente', eles têm suas origens e sua importância na cultura na qual são criados. É esta localização cultural dos significados que garante sua negociabilidade e, no final das contas, sua comunicabilidade" (2001, p. 16).

Diante deste panorama, pode-se realizar uma interlocução com a noção de significado proposta por Aguiar e Ozella (2006), que definem os significados como os conteúdos mais estáveis, compartilhados socialmente, os quais são apropriados pelo sujeito e configurados pela própria subjetividade.

1 De acordo com Vigotski, "A vivência é uma unidade na qual, por um lado, de modo indivisivel, o meio, aquilo que se vivencia está representado - a vivência sempre se liga àquilo que está localizado fora da pessoa - e, por outro lado, está representado como eu vivencio isso, ou seja, todas as particularidades da personalidade e todas as particularidades do meio são apresentadas na vivência". (2010b, p. 686) 
Vigotski (2009), compreende o ser humano enquanto atuante na cultura, visto que, ainda que o sujeito se constitua pela reprodução de condutas e comportamentos sociais, este também cria, e deste modo, é considerado produtor de cultura. Portanto, esta relação dialógica entre o desenvolvimento do sujeito e sua relação com a cultura ocorre por intermédio das principais atividades humanas, reprodução e criação. ${ }^{2}$

Em interlocução com esta ideia, Bruner (2001) anuncia que a pessoa, no exercício da narrativa, negocia significados em uma prática partilhada socialmente, permitindo a construção de novas redes de significações sobre a realidade.

Para Molon (1999), o homem constitui-se pelas significações culturais, contudo a significação se refere à própria ação, pois não existe em si, acontecendo no momento em que os sujeitos entram em relação e passam a significá-la. Isto é, só existe significação quando significa para o sujeito e este adentra o mundo das significações, quando há o reconhecimento do outro.

Deste modo, Molon (1999) esclarece que a mediação dos signos é fundamental para a existência da cultura, uma vez que, desde o nascimento do sujeito, este se relaciona com o outro e se apropria do seu entorno pelo processo de mediação. Contudo, é necessária a compreensão do que se constitui como signo. Pode-se dizer que este corresponde a instrumentos psicológicos que exercem influência

2 Conforme Vigotski (2009), "Se olharmos para o comportamento humano, para a sua atividade, de um modo geral, é fácil verificar a possibilidade de diferenciar dois tipos principais. Um tipo de atividade que pode ser chamado de reconstituidor ou reprodutivo. Está ligado de modo íntimo à memória; sua essência consiste em reproduzir ou repetir meios de conduta anteriormente criados e elaborados ou ressuscitar marcas de impressões precedentes. [...] Além da atividade reprodutiva, é fácil notar no comportamento humano outro gênero de atividade, mais precisamente a combinatória ou criadora [...] que faz do homem um ser que se volta para o futuro, erigindo-o e modificando o seu presente". (2009, p. 11, 13-14) no controle e no domínio do ser humano. Ainda, de acordo com Molon, os signos são:

[...] a linguagem, as formas numéricas e cálculos, a arte e técnica de memorização, o simbolismo algébrico, as obras de arte, a escrita, os gráficos, os mapas, os desenhos, enfim todo gênero de signos convencionais. São específicos da espécie humana. (1999, p. 115)

Assim, pode-se pensar que toda relação humana é mediada pela utilização de signos e instrumentos que operacionalizam toda atividade do ser humano. Seguindo essa lógica, depreende-se que o discurso narrativo é constituído e constitui processos de mediação, dado que esta forma discursiva ocorre na e pela relação constitutiva Eu-Outro, a partir dos signos, da palavra, da semiótica, além de outros instrumentos de mediação. Assim, a relação mediatizada não se limita à presença física do outro, esta é a própria relação. (MOLON, 1999).

Neste aspecto, a narrativa também pode ser compreendida como uma relação social mediatizada, uma vez que o ato narrativo se configura em um processo de significação que possibilita a comunicação entre os sujeitos e a passagem da totalidade às partes, de forma recíproca.

É necessário mencionar que o discurso narrativo se configura por intermédio da apropriação de diferentes modalidades de linguagem. Nesse sentido, pode-se pensar que o desenvolvimento das formas narrativas exercem um papel de atividade-guia, ${ }^{3}$ dado que esta atividade carrega fatores fundamentais e contém elementos estruturantes que impulsionam o desenvolvimento psicológico e afetivo, gerando neoformações psíquicas e ampliando

3 A atividade configura-se enquanto guia porque está carregada de fatores e elementos que impulsionam o desenvolvimento, favorecendo o estabelecimento de novas relações entre pensamento e ação. Esta atividade é modificada a cada estágio de desenvolvimento da criança, e para cada conjunto de vivências, de tal forma que a atividade se constitui enquanto guia para o desenvolvimento psicológico da criança, à medida que produz neoformações psíquicas (PRESTES, 2010). 
o processo de significação da realidade, de modo que potencializa os processos de tomada de consciência do sujeito (PRESTES, 2010).

Bruner (2002) anuncia que a linguagem se configura enquanto o instrumento mais poderoso para a organização da experiência humana, bem como para a criação e a organização da realidade.

Nessa perspectiva, considera-se a linguagem um elemento crucial para se refletir sobre a qualidade dos processos de mediação promovidos, pois, por meio dela, é que se faz possível o estabelecimento de significados compartilhados pelos grupos de pertença, percepções e interpretações de objetos e situações, reafirmando o processo de funcionamento mental humano, com sua gênese nos aspectos sociais, geridos pela cultura, utilizando a mediação simbólica (LIMA; CARVALHO, 2013, p. 161).

Conforme Bruner (1997), a narrativa possibilita o diálogo entre o passado e o futuro. Além disso, a história é narrada a partir de um conjunto de prismas pessoais, permitindo à pessoa interpretar sua vida e criar uma significação pessoal para as experiências vivenciadas. Portanto, a narrativa é polissêmica, uma vez que esta é suscetivel a diversas interpretações e significações que acontecem na prática social.

Bruner (1997) ainda expõe outro atributo da narrativa, ao anunciar que esta pode ser real ou imaginária. Seguindo esta perspectiva, o exercício da narrativa possibilita ao sujeito desenvolver a sua capacidade de imaginação que é interdependente da realidade social. Sob este aspecto, Vigotski (2009) considera que a atividade de imaginação não se limita à perspectiva do não real, pois este a compreende como função mental superior que embasa toda ação ou atividade humana criadora, que se manifesta em todo o campo da vida cultural.
Segundo Vigotski (2009), toda atividade de imaginação ancora-se em elementos tomados da realidade, bem como na diversidade e riqueza do acúmulo de experiência do sujeito. Dito isto em outras palavras, a imaginação se apoia na experiência anterior da pessoa, assim como esta se apoia naquela, considerando que toda imaginação é embasada em elementos da realidade e presentes na experiência anterior, sendo a experiência adquirida nas relações sociais. Deste modo, entende-se que toda criação, por mais individual que seja, possui um coeficiente social, que está permeado por uma colaboração anônima e coletiva de inventores desconhecidos.

Diante deste cenário, torna-se fundamental destacar o conceito de reelaboração criativa (VIGOSTKI, 2009), que se refere à combinação das impressões vivenciadas pelo sujeito. Assim, com base nelas, este pode construir uma realidade nova que corresponda aos seus anseios e às suas aspirações. Desta forma, podese reconhecer o potencial criativo da pessoa na significação do seu entorno social, ao considerar que o desenvolvimento humano está intrinsecamente relacionado à apropriação da cultura, implicando-se a uma participação ativa do sujeito na cultura.

Seguindo esta perspectiva, é necessário salientar que qualquer discurso narrativo propicia espaços paras rupturas e violações, portanto, ainda que pela via de criação de uma narrativa o ser humano corra o risco de reproduzir a realidade hegemônica, ainda assim, por intermédio desta forma discursiva, ele pode propor novas formas de significação da realidade.

Sendo assim, pela via da narrativa, o ser humano, ao criar situações imaginárias, pode apropriar-se tanto da cultura como de seus artefatos culturais. Assim, através da significação de suas vivências, atravessadas pelo mecanismo de reelaboração criativa, este pode 
atribuir novos sentidos sobre a sua realidade social, o que possibilita ao sujeito assumir novas formas de participação na cultura onde está inserido.

Assim, a partir da interlocução teórica anunciada no decorrer deste ensaio, pode-se pensar que $o$ ato narrativo se configura em uma forma discursiva que se apropria de diversas modalidades de linguagem, sendo esta uma ação que pode atuar enquanto atividade guia, potencializadora do desenvolvimento da construção de si, e da relação com o outro. Ao levar em conta tais análises acerca do potencial das narrativas, compreende-se que estas, ao serem partilhadas no interior do grupo terapêutico de adolescentes, possibilitam a elaboração, tanto no âmbito individual como grupal, das vivências que ativam dinâmicas subjetivas, que são qualitativamente distintas.

\section{Metodologia}

Como anunciado anteriormente, o presente trabalho foi realizado no âmbito do CAPSI Curumim, localizado no município de Cuiabá -MT, junto aos/as adolescentes que frequentavam um dos grupos terapêuticos propostos pela referida unidade de saúde mental. Inicialmente, o/as estagiário/as procuraram apreender, ainda que de forma breve, a história dos/ as adolescentes que integravam o grupo em questão. Com base na leitura do Projeto Terapêutico Individual (P.T.I) de cada integrante, do apoio de profissionais técnicos que partilharam algumas experiências, no decorrer das reuniões de miniequipe, e por intermédio das vivências compartilhadas com os/as adolescentes.

Nessa perspectiva, as intervenções psicossociais realizadas no contexto das oficinas socioafetivas seguiram a programação da unidade de saúde, sendo realizadas uma vez por semana, com uma carga horária que variava entre uma e duas horas, conforme as especificidades das atividades desenvolvidas. De modo usual, o grupo era formado por uma a três técnicas de diferentes categorias profissionais, pelos três estagiários de psicologia e pelos adolescentes, com participação em média de dois a seis integrantes, e a idade destes variava entre 14 a 25 anos.

No decorrer da realização do estágio, constatou-se que este grupo terapêutico dos adolescentes que frequentavam a unidade de saúde, na segunda-feira, no período matutino, era compreendido enquanto "agudo". Com base nas reflexões constituintes do Projeto Terapêutico Global (P.T.G) do CAPSI, e em virtude das patologias com as quais estes adolescentes foram diagnosticados, tais como o episódio depressivo grave, com sintomas psicóticos, a esquizofrenia em suas diferentes classificações e o retardo mental moderado, conforme a Classificação Internacional de Doenças e Problemas Relacionados à Saúde (CID-10).

Desta forma, a opção pela realização de intervenções psicossociais, com base em oficinas socioafetivas, teve como objetivo destacar a narrativa e a ludicidade enquanto instrumentos psicológicos de mediação, e promotores de desenvolvimento e dos processos de aprendizagem, os quais favoreceriam o fortalecimento da representação do usuário, enquanto sujeito ativo, que em sua relação com o outro, cria e recria formas de significação da realidade. É preciso destacar, que as oficinas socioafetivas são delineadas enquanto intervenções psicológicas que podem ser realizadas tanto em âmbito grupal como individual.

Pela via da narratividade, a pessoa cria uma situação real ou imaginária, percorre um caminho para o desenvolvimento do pensamento abstrato, cria e negocia significados partilhados na realidade social. Assim, a narrativa pode potencializar processos terapêuticos, uma vez que se configura em uma modalidade 
discursiva que favorece a expressão do sujeito, propiciando a este exercer sua autonomia, criar regras sociais de convivência, elaborar planos e ações conjuntas, que the possibilitam perceber, nestes processos, aspectos de sua autoria nas práticas sociais e culturais.

Sendo assim, os/as adolescentes do grupo de segunda-feira foram convidados/as a construir uma narrativa coletiva, com base na apresentação de uma narrativa encorajadora. As oficinas socioafetivas foram tematizadas a partir da proposta de construção de uma narrativa grupal, que seria delineada por meio da articulação dos enredos desenvolvidos pelos adolescentes, diante da apresentação da narrativa encorajadora, a imagem de um Curumim, um índio criança parcialmente imerso na água. A opção por esta imagem teve como objetivo incitar metáforas que remetessem a ambiguidades, tais como, estranho/familiar, controle/ descontrole.

As intervenções realizadas em campo de estágio e registradas no Caderno de Campo foram interpretadas pela via da análise compreensiva de episódios selecionados. o conteúdo das sessões e suas elaborações teórico-reflexivas foram descritos no referido caderno de campo, que foi utilizado como fonte de informação primária, uma vez que este material contém dados de todas as sessões e intervenções, que foram executadas no decorrer da realização do Estágio Supervisionado e Específico.

Com base nas análises dos episódios advindos dos processos psicossociais desencadeados na construção da narrativa coletiva, será delineado um Estudo de Caso sobre uma das adolescentes que esteve presente em 16 das 37 sessões realizadas. Sendo assim, a integrante será nomeada a partir de letra R., enquanto atribuição de nome fictício, ao ser citada durante a discussão.

\section{Estudo de Caso}

Seguem as apresentações de episódios significativos para a contextualização e a compreensão das mudanças de comportamento e tomadas de posição diferenciadas, que a adolescente R. assumiu no decorrer do processo de construção da narrativa coletiva.

\section{Breve contextualização da história de $\mathrm{R}$}

Neste primeiro momento, torna-se necessário realizar uma breve contextualização da condição psicossocial de R., que se encontra com 16 anos, cursando o segundo ano do ensino médio, em uma escola de ensino regular e pública. $O$ seu primeiro acolhimento foi realizado em 2013. A queixa pela qual foi acolhida se referia ao relato de sua mãe que, na ocasião, descreveu o estado de R., enquanto um aprofundamento de uma sensação de tristeza e uma condição de isolamento que se iniciou após episódios de bullyng que a mesma sofreu na escola, em 2012, sendo esses episódios envolvidos por uma vivência de violência simbólica, a partir de verbalizações com tom pejorativo, advindas de colegas de turma, relacionadas ao seu padrão de beleza física. A hipótese diagnóstica elaborada para a condição de R., conforme os transtornos descritos no CID 10, refere-se à condição de saúde descrita pelo quadro F.32.3, que representa o diagnóstico de episódio depressivo grave, com sintomas psicóticos.

\section{Curumim, a água e o poder da imaginação: delineamento de uma narrativa individual}

Este episódio anuncia a participação da adolescente R. na construção da narrativa, em que os conteúdos individuais expressos, no enredo 
individual construído pela mesma, foram manifestados de forma a delinear-se a construção de sua personagem.

No decorrer das intervenções iniciais em grupo, foi apresentada aos/as adolescentes a narrativa encorajadora, a imagem do Cururim, sendo esta impulsionadora da construção de uma prática partilhada entre os integrantes do grupo. Assim, o/as estagiário/as e a psicóloga técnica da unidade elucidaram alguns questionamentos, partindo das seguintes reflexões: qual ou quais sentimentos eram provocados, a partir do olhar de cada adolescente à imagem; a outra questão referia-se à investigação da água, o que haveria ou poderia conter a água em que o Curumim se encontrava parcialmente imerso.

Desta forma, percebeu-se, nas primeiras sessões, que o enredo individual elaborado pela integrante R. estava permeado por estados emocionais considerados bons, seus desenhos eram compostos por aspectos alegres, e esta, ao relatar os sentimentos que emergiam a partir do contato com a narrativa encorajadora, expressou apenas emoções benevolentes. Porém, no decorrer do processo de mediação, ela se permitiu escrever sentimentos que não lhe suscitavam sensações de bem-estar, dentre eles, medo, pesadelo, cobra e palhaço, mas somente os escreveu no desenho realizado pela estagiária, que estava sentada ao seu lado.

Durante a construção de desenhos, em uma das sessões iniciais, por repetidas vezes, R. perguntava ao/as estagiário/as se seu desenho estava bonito, se estava bom, para, desta forma, continuar prosseguindo. Em determinado momento, R. menciona que perguntara isso, mas que não significava que ela estivesse se sentindo insegura, e, direcionando seu olhar à técnica da equipe, solicitou a ela que não escrevesse isto em seu prontuário, pois ela estava bem. Após o término da atividade,
R. aproximou-se de uma das estagiárias e disse que havia ficado com receio da técnica colocar aquela observação em seu prontuário, pois este documento seria o norte de avaliação que a médica psiquiatra da unidade usaria para analisá-la. E certamente, a partir daquela observação, as possibilidades de suas doses de medicação aumentariam, seriam maiores. Para R., tal fato significaria uma piora em seu estado de saúde, aproximando-a do estado de doença, e, neste sentido, do agravo da condição de um transtorno mental, e também de um lugar de reconhecimento do outro, a partir do paradigma da loucura.

Esta postura mais rígida de R., na relação de negociação com esses significados da cultura, podendo estes serem elencados enquanto o estado de bem-estar, o estado ideal de saúde e saúde mental, e o significado de felicidade, trazidos em seu discurso, guiaram as análises do/as estagiário/as acerca de quais possíveis intervenções poderiam ser realizadas durantes as próximas atividades.

Nessa perspectiva, o/as estagiário/as pensaram enquanto possivel recurso de atuação para esta postura relacional de R., a devolução de perguntas formuladas a partir das falas realizadas por ela mesma, a fim de colocá-la tanto como protagonista do processo de questionamento dessa rigidez, quanto com a intenção de provocar uma mudança em seu meio, que a fizesse transformar este lugar de relação, em referência ao processo de negociação com estes significados. E, assim, possibilitar modificações em suas vivências, e, por conseguinte, dos processos de significação; isto, partindo-se das conversas e relações estabelecidas a partir da continuação da construção da narrativa.

Neste sentido, no episódio que se seguiu, nas sessões em que R. retomou seus questionamentos acerca da escrita no prontuário, quando em certos momentos, durante o en- 
contro em grupo, ela percebia ter demonstrado tristeza e insegurança, ao desenvolver a atividade, as estagiárias e o estagiário incitaram reflexões a partir de questionamentos sobre se R. conseguiria, a partir de suas vivências e seus conhecimentos, nomear alguém que ela conhecesse e interpretasse como saudável e bem, que nunca tivesse apresentado algum comportamento que demonstrasse tristeza, insegurança, agressividade e irritabilidade. R. parou por um instante após as perguntas, e disse que não, que não conhecia ninguém que conseguisse se manter "bem" durante todo o tempo em sua vida. A partir desta reflexão, foi possivel conversar em grupo acerca das idealizações que existem em sociedade sobre os significados dos estados de saúde, bem-estar e felicidade.

Durante as sessões posteriores, o/as estagiário/as apresentaram a proposição aos/ as adolescentes para os mesmos iniciarem a construção do enredo coletivo, partindo-se das construções narrativas individuais. Estas referiam-se à produção dos/as adolescentes que foram realizadas individualmente durante as oficinas socioafetivas, que tinham, como eixo delineador, a narrativa encorajadora, objetivada na imagem do Curumim. As produções citadas envolviam desenhos, trechos escritos de histórias imaginadas, recorte e colagem de imagens, poemas e poesias.

No decorrer das oficinas seguintes foi interessante notar a mudança no comportamento de R. em grupo, ao assumir uma posição central na construção da narrativa. Visto que, por meio da utilização da linguagem enquanto instrumento de mediação das expressões e vivências, esta iniciou sua sugestão de escrita do enredo da narrativa, mencionando então para todos em grupo, que a história poderia começar assim: "Era uma vez um Curumim que tinha medo das pessoas fazerem maldade com ele" (R., feminina, 16 anos), logo ela se descul- pa, e diz que prefere substituir "pessoas" por “inimigos", refazendo o enredo.

É importante mencionar que R., ao chegar na unidade, apresentava muita dificuldade de se expor, mais fisicamente, mas também pela fala. Porém, ao colocar-se como figura central e impulsionadora dos processos de síntese para a construção do enredo coletivo, ela demonstra engajar-se em um processo de mudança na relação de si com o grupo. $E$ pensando sobre esta relação eu-outro, podese considerar a possibilidade desta ação tê-la impactado subjetivamente, em seus processos de negociação de significados com a cultura, a partir da elaboração de conteúdos, pela história, utilizando-se da imaginação; e pela interação em grupo, uma vez que as cenas e as partes do enredo eram encaminhadas, a partir do consenso do grupo.

\section{O desenvolvimento do Curumim e o encontro com Liza: mobilização do sentimento de pertença}

O desenrolar da narrativa do Curumim evidencia os processos de negociação entre a adolescente e os demais integrantes do grupo, uma vez que é apresentado no início da história um Curumim mais infantilizado, que a partir das experiências vivenciadas na floresta, permeadas por encontros com outros atores sociais, torna-se adulto, aos poucos, encontrando até mesmo uma companheira romântica.

Sob este aspecto, durante as sessões, a adolescente R. apresenta uma sugestão quando o grupo inicia a articulação da história com os desenhos selecionados, "poderíamos dizer que aconteceu uma grande aventura, que lá ele descobriu o bem e o mal" (R., feminina, 16 anos). No transcorrer das sessões o/as estagiário/as junto aos/as adolescentes pensaram o que poderia constituir essa grande aventura vivenciada pelo Curumim, R. sugere que se 
pode pensar que: "Ele teve que passar pelos mares, rios até chegar nesse lugar bonito, passou pelos peixes, cobras, animais, chuva, sol, tempestade" (R., feminina, 16 anos).

Essas situações em que o Curumim se expôs, ao ir para a floresta, foram discutidas em grupo, e o/as estagiário/as perguntaram aos integrantes se estes achavam que o Curumim estava sozinho ou acompanhado. Todos os adolescentes do grupo disseram que o Curumim estava sozinho, mas que encontraria pessoas durante estes caminhos. Um dos adolescentes do grupo sugere que uma das pessoas que o Curumim iria encontrar poderia ser "Um pescador, que ajuda ele, explicando para achar o caminho e esse pescador dá um peixe para ele comer"; R. complementa que para encontrar esse caminho, "O Curumim segue o coração dele, para o lugar certo" (R., feminina, 16 anos). Uma das estagiárias interviu questionando como será que o Curumim havia parado na floresta, R. sugere que "Os pais dele saíram e deixaram ele sozinho em casa, e ele fugiu de casa. Ele tinha dúvidas de como seria a floresta e o mundo lá fora, então ele "fugiu para descobrir essas aventuras" (R., feminina, 16 anos).

Assim, durante a construção da narrativa, observou-se uma mudança significativa nos comportamentos da adolescente R., que, inicialmente, se apresentava rigidamente em suas ações, orientadas pelas significações idealizadas do estado de bem-estar, saúde e felicidade, juntamente a questionamentos sobre o conteúdo presente em seu prontuário. No decorrer das intervenções, a adolescente assumiu o papel de protagonista das situações que construiu para o enredo coletivo, elaborando metáforas a partir de uma posição de enfrentamento diante do desconhecido, e também de modo ativo na construção de novas relações.

Outro aspecto necessário a ser mencionado, refere-se à personagem Liza, construída por R., que também revela o movimento de busca da adolescente por pertença ao grupo, à medida em que esta, uma das únicas meninas, cria a única personagem feminina na narrativa, com a qual estabelece uma relação de identificação.

Nesse tempo todo enquanto ele andava por lugares conhecidos e desconhecidos na floresta, e depois de ter percebido que havia crescido. Ele conheceu uma amiga, no meio da floresta, Liza. Quando os dois se encontraram, ela falou com ele que queria o seu bem, porque foi amor à primeira vista. No momento em que Liza encontrou o Curumim, ela estava colhendo frutas nas árvores. Ela perguntou se ele tinha alguém. o Curumim respondeu que ele não tinha ninguém, então os dois namoraram. (R., feminina, 16 anos).

Depreende-se, então, que a mediação semiótica (MOLON, 1999) presente nas relações sociais, o processo de significação partilhado entre estes, que ocorreu de forma dialógica na e pela linguagem, no confronto da relação eu-outro, pode ter contribuído para a emergência de um sentimento de pertença grupal, bem como colaborado para a busca da reorganização da rede de significações partilhadas socialmente, que estavam atravessadas por paradigmas manicomiais.

Desta forma, no decorrer das oficinas, foi possivel verificar também que R. e os demais integrantes do grupo partilhavam das angústias em relação à "normalidade", aos padrões de beleza, às situações de bullying, às dificuldades encontradas na condução de suas relações afetivas, seja com amigos (e a falta de) ou familiares, a exclusão do convívio social e as condições de sofrimento e fragilização psíquica. Estas relações sociais de compartilhamento em grupo tiveram como alicerce a criação da narrativa do Curumim, que impulsionou os adolescentes a partilharem, entre si, suas potencialidades de negociação e significações dos conflitos e angústias que permeiam suas histórias de vida. 
Nesse sentido, observou-se ainda no processo de criação do título da narrativa nomeada, Os desbravadores, criado pela integrante R., e consentido pelos demais adolescentes, que se tornou concreto o movimento de explorar o não familiar. Pode-se pensar que as vivências que constituíram o processo de criação da narrativa produziram novas formas de R. se manifestar, diante do preconceito, do estigma e da exclusão social que atravessa a realidade social vivenciada por ela. Sendo essa observação válida para os comportamentos manifestos da adolescente R. em grupo. Assim, compreende-se que esta atividade de criar histórias, a partir da imaginação de um lugar diferenciado para si, apontou para a noção de pertencimento construída com o grupo enquanto eixo potencializador da significação de si em relação com o outro.

\section{Considerações finais}

O trabalho realizado na referida unidade de saúde mental com o grupo de adolescentes mencionado, em especial a exemplificação do processo, aqui apresentado, por meio do estudo de caso feito a partir das reflexões acerca das mudanças de comportamento da adolescente R., sugere contribuições reflexivas para se pensar nas potencialidades terapêuticas do trabalho com narrativas, como instrumento de intervenção no campo da saúde mental.

\section{Referências}

AGUIAR, W, M, J.; OZELLA, S. Desmistificando a concepção de adolescência. Cadernos de pesquisa, v. 38, n. 133, p. 97-75, jan./abr.2008.

AGUIAR, Wanda Maria Junqueira; OZELLA, Sergio. Núcleos de significação como instrumento para a apreensão da constituição dos sentidos. Psicologia Ciência e Profissão, Brasília, v.26, n. 2, p. 222 - 245, jun. 2006.

ANDRADE, D. B. S. F. Rede de apoio à Educação Infan-
A opção pela utilização de uma narrativa encorajadora para as intervenções nas oficinas socioafetivas possibilitou a realização de um trabalho que se consolidasse em uma perspectiva não hegemônica, em referência ao paradigma tradicional da clínica. Deste modo, a narrativa pôde potencializar processos terapêuticos, posto que se observou a importância desse instrumento psicológico como uma metodologia pertinente aos conteúdos expressados e enunciados pelos sujeitos no processo de construção da narrativa Curumim, durante a realização das oficinas socioafetivas. Diante da possibilidade de construção de enredos narrativos, o adolescente pôde imaginar, criar e negociar significados na elaboração de conteúdos relacionados aos processos de significação do meio, atribuir novas significações às suas vivências, o que pode propiciar transformações na compreensão deste sobre seu meio, e influenciá-lo nos processos de tomada de consciência de si.

Nesse contexto, a finalidade das intervenções psicossociais foi possibilitar a criação de espaços que impulsionassem uma relação de emancipação, principalmente em relação à linguagem, às expressões de seus sofrimentos. Nessa relação psicoterapêutica, o sujeito foi compreendido com um ser ativo, em seus processos de transformação, subjetivação e significação da própria realidade.

til: interfaces com a Psicologia, Pedagogia, Arquitetura e Música. Projeto de Extensão. Cuiabá, 2015.

BRUNER, Jerome. Atos de significação. Porto Alegre: Artes Médicas, 1997.

BRUNER, Jerome. A cultura da educação. Porto Alegre: Artes Médicas, 2001.

BRUNER, Jerome. Realidade mental, mundos possiveis. Tradução de Marcos A. G. Domingues. Porto Alegre: Artmed, 2002. 
DUVEEN, G.; LLOYD, B. Las representaciones sociales como una perspectiva de la psicología social. In: CASTORINA, J. A. (Org.). Representaciones sociales: problemas teóricos y conocimientos infantiles. Buenos Aires: Ed. Gedisa, 2008. p. 29-39

JOVCHELOVITCH, Sandra.; BAUER, Martin W. Entrevista narrativa. In: BAUER, M. W.; GASKELL, G. Pesquisa qualitativa com texto, imagem e som. Tradução de Pedrinho Guareschi. Petrópolis, RJ: Vozes, 2002, p. 90-113.

LIMA, Paula Márcia de.; CARVALHO, Carolina Freire de Carvalho de. A Psicoterapia Socio-Histórica. Psicologia: Ciência e Profissão, v. 33 (Número Especial), p. 154-163, 2013.

\section{MOLON, S. I. Subjetividade e constituição do sujeito} em Vygotsky. São Paulo: EDUC, 1999.

\section{MOLON, S. I. Cultura - A dimensão psicológica e a} mudança histórica e cultural. Trabalho apresentado na III Conferência de Pesquisa Sócio-cultural, Campinas, SP. 2000. Disponivel em: $<$ www.fae.unicamp. br/br2000/trabs/2330.doc >. Acesso em: 15 Jul. 2015.
MOLON, Susana Inês. Notas sobre constituição do sujeito, subjetividade e linguagem. Psicol. estud., Maringá, v. 16, n. 4, Dec. 2011.

PRESTES, Zoia Ribeiro. Quando não é quase a mesma coisa: análise de traduções de Lev Semionovitch Vigotski no Brasil. Repercussões no campo educacional. 2010. 295 f. Tese (Doutorado em Educação) - Faculdade de Educação, Universidade de Brasília, Brasília, DF, 2010.

VIGOTSKI, L. S. Imaginação e criação na infância: ensaio psicológico: livro para professores. Apresentação e comentários de Ana Luiza Smolka. Tradução de Zoia Ribeiro Prestes. São Paulo: Ática, 2009.

VIGOTSKI, Lev S. Psicologia pedagógica. São Paulo: Editora WMF Martins Fontes, 2010a.

VIGOTSKI, Lev Semionovich. Quarta Aula: a questão do meio na pedologia. Tradução de Márcia Pileggi. Psicologia USP, São Paulo, v. 21, n. 4, p. 681-701, 2010b.

Recebido em: 15.01.2016. Aprovado em: 10.03.2016.

Ruzia Chaouchar dos Santos é mestranda no Programa de Pós-graduação em Educação (PPGE), pela Universidade Federal de Mato Grosso (UFMT), campus Cuiabá. Graduada em Psicologia pela mesma Universidade, com ênfase curricular em Intervenções em Processos de Saúde e Sofrimento Psíquico. Atualmente é bolsista da CAPES, e integrante do Grupo de Pesquisa em Psicologia da Infância (GPPIN/UFMT) e do Grupo de Estudos e Pesquisas em Psicologia e Educação de Mato Grosso (GEPPEMAT/UFMT). E-mail: ruziachauchar1@gmail.com

Naiana Marinho Gonçalves é Bacharel em Psicologia, pela Universidade Federal de Mato Grosso, campus Cuiabá, com ênfase curricular em Intervenções em Processos de Saúde e Sofrimento Psíquico. No presente momento, atua enquanto Pesquisadora no Grupo de Pesquisa em Psicologia da Infância (GPPIN/Programa de Pós-Graduação em Educação da UFMT), e investiga principalmente temáticas voltadas aos processos de desenvolvimento humano, partindo das discussões concernentes à Teoria das Representações Sociais, Psicologia Histórico-Cultural, Psicologia do Desenvolvimento e Aprendizagem, Educação Infantil e Estudos sobre Narrativas. E-mail: goncalvesnai@gmail.com

Henrique Araujo Aragusuku é Graduado em Psicologia, pela Universidade Federal de Mato Grosso; possui experiência de atuação na rede pública de saúde mental, a partir de estágio, pelo PET/Redes, no Centro de Atenção Psicossocial Álcool e Outras Drogas (2014-2015), e de estágio supervisionado no Centro de Atenção Psicossocial Infanto-Juvenil (2015). Tem experiência de pesquisa nas temáticas: Estado e políticas públicas, movimentos sociais e movimento LGBT, políticas de diversidade sexual e de gênero, psicologia e direitos humanos. E-mail: henriquearagusuku@gmail.com

Daniela Barros da Silva Freire Andrade é Professora Adjunta da Universidade Federal de Mato Grosso (UFMT), Curso de Psicologia, Coordenadora do Grupo de Pesquisa em Psicologia da Infância (GPPIN), da Universidade Federal de Mato Grosso (UFMT). E-mail: freire.d02@gmail.com

Rua cinco, n. 6, Setor Oeste - Morada do Ouro

Cuiabá - Mato Grosso

CEP: $78053-218$ 